Article

\title{
Efficacy of Treatments against Garlic Mustard (Alliaria petiolata) and Effects on Forest Understory Plant Diversity
}

\author{
Lindsey M. Shartell *, Linda M. Nagel and Andrew J. Storer \\ School of Forest Resources and Environmental Science, Michigan Technological University, \\ 1400 Townsend Drive, Houghton, MI 49931, USA; E-Mails: 1mnagel@mtu.edu (L.M.N.); \\ storer@mtu.edu (A.J.S.)
}

* Author to whom correspondence should be addressed; E-Mail: 1msharte@mtu.edu.

Received: 1 June 2012; in revised form: 17 July 2012 / Accepted: 19 July 2012 /

Published: 3 August 2012

\begin{abstract}
Garlic mustard, an invasive exotic biennial herb, has been identified in the Upper Peninsula of Michigan, but is not yet widely distributed. We tested the effectiveness and impact of management tools for garlic mustard in northern hardwood forests. Six treatment types (no treatment control, hand-pull, herbicide, hand-pull/herbicide, scorch, and hand-pull/scorch) were applied within a northern hardwood forest invaded by garlic mustard. We sampled understory vegetation within plots to compare garlic mustard abundance (distinguishing first and second year plants) and native plant diversity before and after treatment. Results immediately following treatment indicated that garlic mustard seedling abundance was significantly reduced by herbicide, hand-pull/herbicide, scorch, and hand-pull/scorch treatments, and that adult abundance was reduced by all treatments. However, sampling of treatment sites one year later showed an increase in seedling abundance in herbicide and hand-pull/herbicide plots. Adult garlic mustard abundance after one year was lower than the control with the exception of the hand-pull plots where adult abundance did not differ. After one year, understory species richness and Shannon's Diversity were lower in the herbicide and pull/herbicide treatments. Based on these results, we conclude that single-year treatment of garlic mustard with hand-pulling, herbicide, and/or scorching is ineffective in reducing garlic mustard abundance and may inadvertently increase the success of garlic mustard, while negatively impacting native understory species.
\end{abstract}


Keywords: invasive plants; northern hardwoods; Upper Michigan

\section{Introduction}

Garlic mustard (Alliaria petiolata (Bieb.) Cavara and Grande) is a common invader of forests in the Midwestern United States. It is an obligate biennial herb in the mustard family (Brassicaceae), which can be identified by its heart-shaped, coarsely-toothed leaves, white flowers, and seeds in slender pods. Garlic mustard is native to northern Europe, and was first documented in North America on the east coast in 1868 [1]. Since then it has become widely established across eastern and central North America. The rapid invasion of garlic mustard is facilitated by high seed production and biennial life cycle. The seeds are held in siliques, and a single, robust plant can have as many as 7900 seeds [1] that can persist in the seed bank for many years [2]. Seeds fall within two meters of the parent plant, with most seeds germinating within one meter creating thick patches that compete with native vegetation $[3,4]$. Additionally, adult plants grow rapidly in early spring when many native plants are still dormant [5]. In Michigan, garlic mustard is commonly found invading deciduous forests, roadsides, and urban areas [6]. It has been identified at a number of locations in the Upper Peninsula of Michigan, but is not yet widely distributed in this area [7].

Treatment methods for managing garlic mustard have included hand pulling, cutting, herbicide application, scorching, and prescribed fire [8]. Biological control using insects or fungi has also been considered, and is anticipated to be an option in the future $[9,10]$. Although treatment methods are commonly applied, little formal testing has been done to determine their effectiveness or impact on native vegetation, and studies that have been reported have shown mixed results. Fire, herbicide, and cutting treatment methods were assessed in a prior study which concluded that any of the methods could be used successfully for short-term control [8], though the impacts on native vegetation were not reported. Another study found that burning of garlic mustard resulted in an increase in stem density and evidence of changes in the native plant community [11]. To further our knowledge of treatment effects on both garlic mustard and native vegetation we applied and evaluated three common treatment methods: hand-pulling, herbicide application, and scorching. Our objectives were first to evaluate the efficacy of treatment methods for reducing garlic mustard seedling and adult abundance at invaded sites, and second to determine the effect of treatment methods on understory plant diversity and regeneration.

\section{Methods}

The study site was located on private land adjacent to the Hiawatha National Forest in Alger County in the Upper Peninsula of Michigan. The site lies within the Au Train River watershed, adjacent to the watercourse, and consists of a northern hardwood forest community dominated by sugar maple (Acer saccharum), with a habitat type of AFOAs (Acer saccharum-Fagus grandifolia/Osmorhiza claytoni-Arisaema atrorubens, [12]). This habitat type is classified as mesic, with rich soil nutrients and high productivity for the region [12]. To determine the extent of the garlic mustard invasion and identify appropriate locations for research plots, we completed a survey of the garlic mustard 
population in June 2005. We mapped locations of garlic mustard using a Trimble Geo XT (Trimble Navigation Limited) geographic positioning system (GPS) receiver. Individual plants and small patches of garlic mustard were located by walking transects spaced $40 \mathrm{~m}$ apart. When large patches of garlic mustard were encountered, the boundary was mapped by following the patch outline. At the site, garlic mustard was found to occur over an estimated 32 hectares, with heavily invaded areas existing along road edges and in a core area of approximately 10 hectares that is separated by roads into three contiguous forest patches.

In May 2006, we established four treatment blocks within each of the three forest patches. Plots were $12 \mathrm{~m} \times 8 \mathrm{~m}$ and contained six unique treatment areas, each $4 \mathrm{~m} \times 4 \mathrm{~m}$ (Figure 1). This resulted in a total sample size of $\mathrm{N}=72$ plots, with $\mathrm{N}=12$ plots available for each of six treatment types. Plots were laid out along the cardinal directions, using a compass and tape to establish proper dimensions. We marked the locations of plots using stakes in conjunction with flags at the corners, as well as flags at the corners and center of every $4 \mathrm{~m}^{2}$ treatment area to note the divisions between treatments. Prior to treatment, understory vegetation was sampled and averaged for two $1 \mathrm{~m}^{2}$ quadrats located near the center of the treatment areas to reduce effects from outside the plot or from adjacent treatments (Figure 1). The number of individuals was recorded for all species present, including woody understory plants and tree seedlings. Garlic mustard seedlings and adult plants were counted separately.

Figure 1. Layout and dimensions of treatment plots $(4 \mathrm{~m} \times 4 \mathrm{~m}$ areas $)$ and vegetation sampling quadrats within treatments (Q1 and Q2).

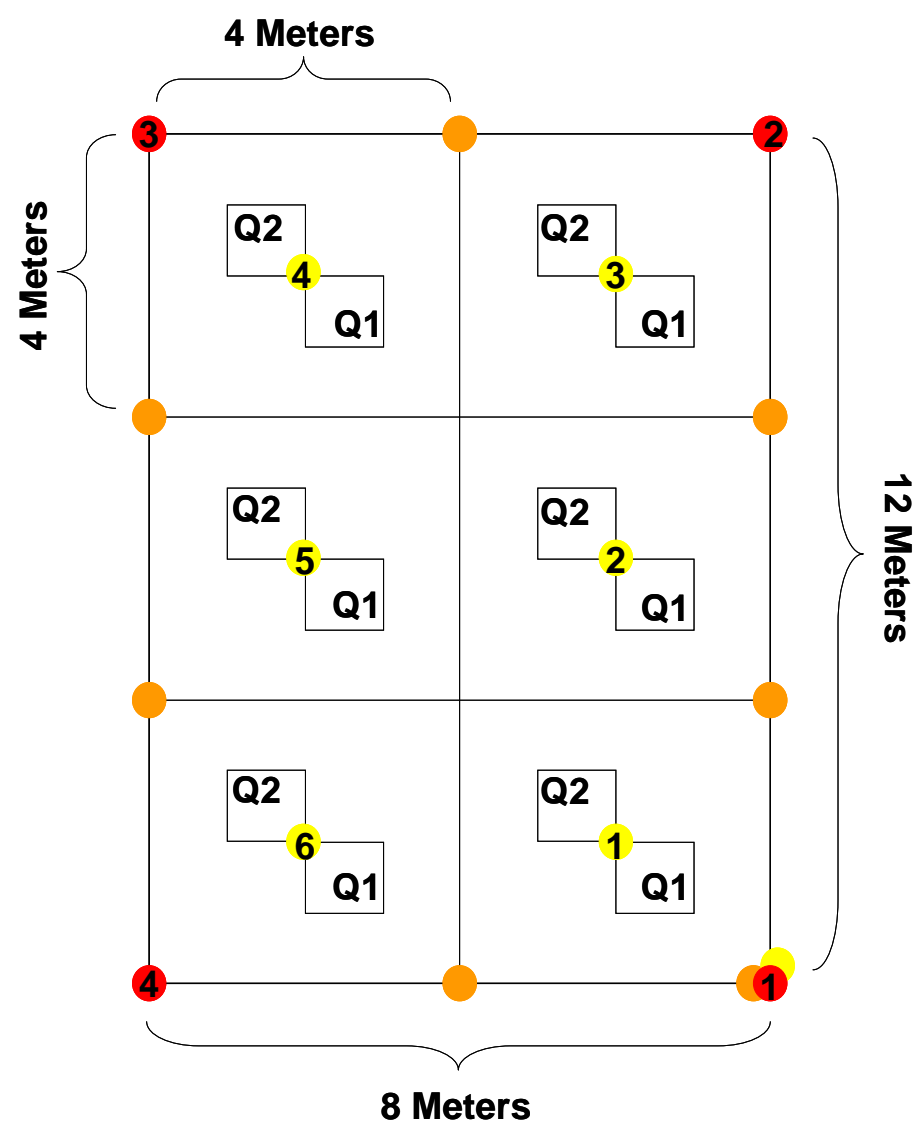


Immediately following plot establishment and pre-treatment understory vegetation assessment (May 2006), we randomly assigned and applied each of the six treatments (control representing no treatment, hand-pull, herbicide, pull/herbicide, scorch, and hand-pull/scorch) to the treatment blocks. The hand-pull treatment consisted of pulling all adult garlic mustard plants within the treatment area, bagging and removing them from the site. For the herbicide treatment, a 5\% glyphosate solution (diluted from an initial concentration of $41 \%$ ) was sprayed evenly over the area using a low-volume hand-held sprayer. The scorch treatment was applied using a propane torch (Flame Engineering Inc., Model VT 3-30C) to burn the treatment area leaving minimal green vegetation. Pull/herbicide and pull/scorch treatments were combinations of hand-pull followed immediately by either herbicide application or scorching. The treatments were implemented over two days, under fair weather conditions $\left(59-77^{\circ} \mathrm{F}\right.$, mostly sunny, winds $<10 \mathrm{mph}$ ). Care was taken during application to ensure that treatments remained within the appropriate areas and that trampling within plots was limited.

Understory vegetation was re-measured at one month (June 2006) and at one year following treatment (June 2007). We analyzed the data using the statistical program R [13]. Garlic mustard seedling and adult abundances were analyzed separately. Means and standard errors $( \pm 1$ SE) were calculated for garlic mustard abundance in each treatment type for each point in time. Analysis of variance (ANOVA) was used to test for differences among plots prior to treatment and in the control treatment over time (May 2006, June 2006, June 2007). Tukey's Honestly Significant Difference (Tukey HSD) was used to test for significant differences between treatments and the control. For all analyses significance was determined at $\alpha=0.05$. We computed diversity indices, in particular species richness and Shannon's Diversity Index (H), using PAST [14]. Diversity indices were also analyzed using ANOVA and Tukey HSD to test the significance of differences between treatment methods.

\section{Results and Discussion}

Within treatment plots garlic mustard was the dominant understory species present. Prior to treatment (May 2006), abundance of garlic mustard seedlings and adults across plots did not significantly differ $\left(\mathrm{F}_{5,66}=0.20, p=0.96\right.$ seedlings, $\mathrm{F}_{5,66}=0.91, p=0.48$ adults $)$. Mean garlic mustard abundance ranged from $15.4( \pm 4.7)$ to $24.3( \pm 11.7)$ seedlings and $8.0( \pm 1.2)$ to $15.5( \pm 4.8)$ adult plants per $1 \mathrm{~m}^{2}$ area (Figures $2 \mathrm{a}$ and $2 \mathrm{c}$ ). In control plots, there was no significant change in garlic mustard abundance for seedlings or adults over time (compared among May 2006, June 2006, and June 2007, $\mathrm{F}_{2,33}=0.99, p=0.39$ seedlings, $\mathrm{F}_{2,33}=0.71, p=0.50$ adults). One month after treatment garlic mustard seedling abundance in the hand-pull treatment was higher $(29.9 \pm 6.4)$ than that in the control plots $(19.2 \pm 3.1)$ but did not significantly differ $(p=0.11)$. Seedling abundance in the herbicide $(0.13 \pm 0.13$ seedlings $)$, pull/herbicide $(0.29 \pm 0.16$ seedlings $)$, scorch $(0.29 \pm 0.21$ seedlings $)$, and pull/scorch treatments $(0.17 \pm 0.09$ seedlings $)$ was significantly lower than the control $(p<0.01$ in all cases). Adult garlic mustard abundance after one month was significantly lower than the control $(10.7 \pm 2.0)$ for all treatments $(p<0.01$ in all cases). After one month no adult garlic mustard was present in the herbicide, pull/herbicide, and scorch treatments, while the hand-pull treatment and pull/scorch treatment had a mean adult abundance of $2.6( \pm 0.7)$ and $0.04( \pm 0.04)$ adults, respectively. After one year, mean garlic mustard seedling abundance was significantly higher when compared to the control $(23.4 \pm 4.1$ seedlings $)$ for the herbicide $(62.7 \pm 11.2, p=0.01)$ and pull/herbicide 
$(65.0 \pm 9.4, p<0.01)$ treatments (Figure $2 \mathrm{~b})$. Seedling abundance did not significantly differ from the control for the hand-pull $(27.9 \pm 4.3, p=0.99)$, scorch $(42.4 \pm 9.2, p=0.56)$ and pull/scorch treatments $(50.1 \pm 7.5, p=0.19)$. Mean adult garlic mustard abundance after one year did not differ from the control $(12.8 \pm 1.8$ adults $)$ in the hand-pull plots $(17.4 \pm 2.5, p=0.12)$. All other treatments had significantly lower abundance of adult plants as compared to the control ( $p<0.01$ for all, Figure $2 \mathrm{~d})$.

Figure 2. Garlic mustard abundance for (a) seedlings before treatment; (b) seedlings one year after treatment; (c) adults before treatment and (d) adults one year after treatment at $\mathrm{N}=12$ plots per treatment. Boxes represent the middle $50 \%$ of the data, with the centerline showing the median and the whiskers showing values that fall within 1.5 times the interquartile range.
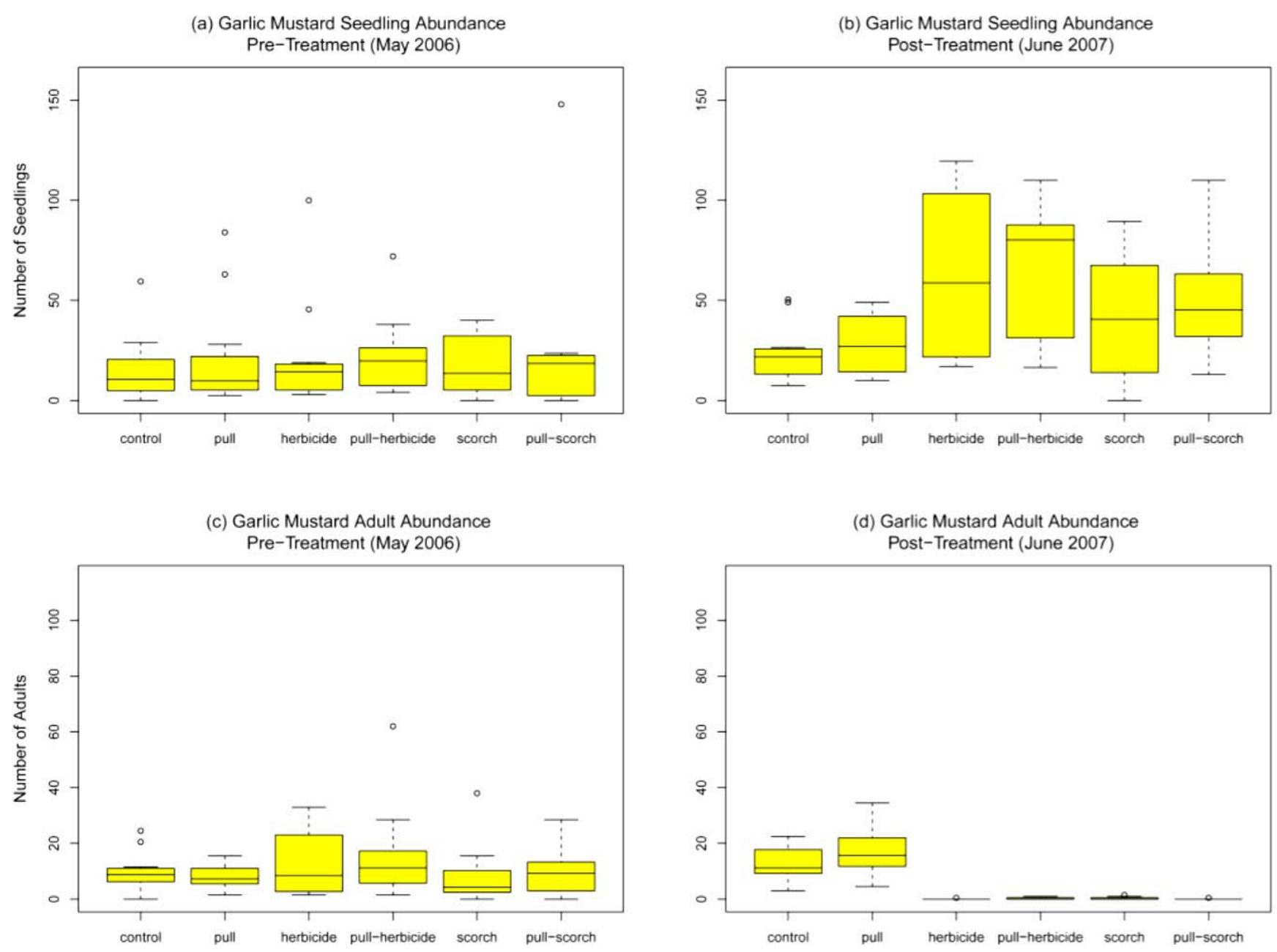

Before treatment, species richness did not differ among plots $\left(\mathrm{F}_{5,66}=0.51, p=0.77\right)$, and ranged from 2 to 9 species per $1 \mathrm{~m}^{2}$ quadrat, with a mean of $4.6( \pm 0.14)$ species. Species composition consisted mainly of native plant species, with the exception of garlic mustard, forget-me-not (Myosotis spp.), and honeysuckle (Lonicera spp.), with the latter two being relatively rare. The most common species within plots included hemp nettle (Galeopsis tetrahit), sugar maple seedlings (Acer saccharum), violets (Viola spp.), and large-flowered trillium (Trillium grandiflorum). Mean Shannon's Diversity also did not differ before treatment $\left(\mathrm{F}_{5,66}=0.18, p=0.97\right)$, and averaged 
0.99 ( \pm 0.03$)$. Species richness did not differ over time for control plots $\left(F_{2,33}=1.15, p=0.33\right)$, nor did Shannon's Diversity $\left(\mathrm{F}_{2,33}=2.80, p=0.08\right)$. One month following treatment, species richness as well as Shannon's Diversity dropped in the herbicide, pull/herbicide, scorch, and pull/scorch treatment plots as compared to the control (Table 1). After one year however, species richness was significantly less than the control for only the herbicide $(p<0.01)$ treatment (Table 1). Shannon's Diversity after one year was lower under herbicide treatments, but was not significantly different than the control (Table 1).

Table 1. Mean understory plant species richness $(\mathrm{R})$ and Shannon's Diversity $(\mathrm{H})$ before and after treatments aimed at reducing the abundance of garlic mustard. Treatments that significantly differed from the control $(p \leq 0.05)$ are indicated by *.

\begin{tabular}{lcccccccc}
\hline & \multicolumn{2}{c}{ Pre-treatment } & May 2006 & & \multicolumn{2}{c}{ Post-treatment June 2006 } & & \multicolumn{2}{c}{ Post-treatment June 2007 } \\
\cline { 2 - 3 } & $\mathbf{R}$ & $\mathbf{H}$ & & $\mathbf{R}$ & $\mathbf{H}$ & & $\mathbf{R}$ & H \\
\hline Control & 4.79 & 1.05 & & 3.96 & 0.75 & & 4.33 & 0.83 \\
Hand-pull & 4.92 & 1.01 & & 4.38 & 0.87 & & 4.04 & 0.76 \\
Herbicide & 4.38 & 0.97 & & $0.66 *$ & $0.12 *$ & $2.71 *$ & 0.49 \\
Pull/herbicide & 4.75 & 0.99 & & $0.79 *$ & $0.14 *$ & & 3.08 & 0.53 \\
Scorch & 4.29 & 0.98 & & $2.29 *$ & 0.50 & & 4.33 & 0.87 \\
Pull/scorch & 4.75 & 0.96 & & $2.08 *$ & 0.50 & & 4.13 & 0.76 \\
\hline
\end{tabular}

Treatments implemented in this study were intended to suppress garlic mustard; however they proved not to be effective after one year. Though garlic mustard adult abundance was significantly lower following treatment, it is unlikely that this decrease will last over time. In herbicide, scorch, and combination treatments, garlic mustard seedling abundance after one year increased compared to the control and hand-pull treatments. This may be due to recruitment of garlic mustard from outside the treatment plots or from the seed bank, the treatment effect on native plants, and/or the rapid germination and competitive behavior of garlic mustard compared to native plants [15]. In addition, the increase in seedling abundance following treatment could be attributable to a release from intraspecific competition from adult garlic mustard plants [16]. Supporting this, is the finding that under the hand-pull treatment (where seedlings were not pulled) adult garlic mustard abundance one year later remained high, and seedling abundance was not increased, suggesting that the adults present may be limiting seedling abundance.

Relatively low species richness and Shannon's Diversity prior to treatment could be in response to invasion by garlic mustard, which has been shown to decrease native plant diversity [4]. An immediate decrease in species richness was expected under herbicide and scorch treatments due to non-target injury. After one year, species richness was still lower in the treatments using herbicide, but not in treatments using scorching. This suggests that herbicide use has a greater effect on native understory plants than scorch or hand-pull treatments. Timing of herbicide use in our study was early spring (May), when garlic mustard adults were beginning to flower but not maturing seed. This corresponded with the growing season for spring ephemerals at the site, which increased non-target impacts of treatment. While early spring application of herbicide has been recommended to minimize impacts to native plants [17], fall herbicide application may be more advantageous [18,19], and would be expected to have limited the impact to understory diversity that was found in our study. 
Garlic mustard abundance after one year indicated that a single treatment, whether hand-pulling, herbicide application, or scorching, is not sufficient to control established populations and may increase the success of garlic mustard. Repeated treatments of garlic mustard in heavily invaded sites using herbicide over multiple years have shown effectiveness in reducing adult plants [18,20]. Where forest understory has also been assessed, multiple year treatment with herbicide and fall application has shown minimal effects on species diversity, with some changes in community composition [18,19]. Despite this, treatment techniques that do not remove all of either cohort, seedlings or adults, may not be sufficient to control garlic mustard populations over time [2]. In our study, herbicide, scorch, and combination treatments had a high rate of success in removing existing adult garlic mustard plants, however they were not as successful in treating garlic mustard seedlings. Furthermore, existing seed banks of garlic mustard can persist in the soil for many years providing a source for re-establishment following treatment [2]. Land managers should avoid single-year treatment of garlic mustard, especially when using herbicide, scorching, or other techniques that harm native plant communities. When multiple year management is not planned for or feasible, treatment should be avoided.

\section{Conclusions}

The results from this research indicate that garlic mustard treatment applied only once may unintentionally enhance the invasion of garlic mustard rather than suppress it. Furthermore, spring herbicide application resulted in a decrease in native plant community diversity that was less evident when using hand-pulling and scorch treatments. Effective treatment of garlic mustard will likely require multiple years of treatment, fall application when using herbicide, high success rates, and consideration for the protection and recolonization of native understory plants at treatment sites.

\section{Acknowledgments}

We thank Jess Barden and Michelle Latsch for their assistance in treatment application and data collection. Funding for this research was provided by the United States Forest Service. Project cooperators included the Michigan Department of Natural Resources, the Michigan Department of Transportation, the Michigan Invasive Plant Council, The Nature Conservancy, Wisconsin Public Works, The Forest-Land Group, and Michigan Technological University.

\section{Conflict of Interest}

The authors declare no conflict of interest.

\section{References}

1. Nuzzo, V.A. Distribution and spread of the invasive biennial Alliaria petiolata (garlic mustard) in North America. In Biological Pollution: The Control and Impact of Invasive Exotic Species; McKnight, B.N., Ed.; Indiana Academy of Science: Indianapolis, IN, USA, 1993; pp. 137-146.

2. Pardini, E.A.; Drake, J.M.; Chase, J.M.; Knight, T.M. Complex population dynamics and control of the invasive biennial Alliaria petiolata (garlic mustard). Ecol. Appl. 2009, 19, 387-397. 
3. Drayton, B.; Primack, R.B. Experimental extinction of garlic mustard (Alliaria petiolata) populations: Implications for weed science and conservation biology. Biol. Invasions 1999, 1, 159-167.

4. Stinson, K.; Kaufman, S.; Durbin, L.; Lowenstein, F. Impacts of garlic mustard invasion on a forest understory community. Northeast. Nat. 2007, 14, 73-88.

5. Anderson, R.C.; Dhillion, S.S.; Kelley, T.M. Aspects of the ecology of an invasive plant, garlic mustard (Alliaria petiolata), in central Illinois. Restor. Ecol. 1996, 4, 181-191.

6. Voss, E.G. Michigan Flora. Part II Dicots; Cranbrook Institute of Science and University of Michigan Herbarium: Ann Arbor, MI, USA, 1985.

7. Shartell, L.M.; Nagel, L.M.; Storer, A.J. Multi-criteria risk model for garlic mustard (Alliaria petiolata) in Michigan's Upper Peninsula. Am. Midl. Nat. 2011, 165, 116-127.

8. Nuzzo, V.A. Experimental control of garlic mustard (Alliaria petiolata (Bieb.) Cavara and Grande) in northern Illinois using fire, herbicide, and cutting. Nat. Areas J. 1991, 11, 158-167.

9. Blossey, B.; Nuzzo, V.; Hinz, H.; Gerber, E. Developing biological control of Alliaria petiolata (M. Bieb.) Cavara and Grande (garlic mustard). Nat. Areas J. 2001, 21, 357-367.

10. Evans, J.A.; Landis, D.A. Pre-release monitoring of Alliaria petiolata (garlic mustard) invasions and the impacts of extant natural enemies in southern Michigan forests. Biol. Control 2007, 42, 300-307.

11. Luken, J.O.; Shea, M. Repeated prescribed burning at Dinsmore Woods State Nature Preserve (Kentucky, USA): Responses of the understory community. Nat. Areas J. 2000, 20, 150-158.

12. Burger, T.L.; Kotar, J. A Guide to Forest Communities and Habitat Types of Michigan; Department of Forest Ecology and Management, University of Wisconsin: Madison, WI, USA, 2003.

13. R Development Core Team. R: A Language and Environment for Statistical Computing; $\mathrm{R}$ Foundation for Statistical Computing: Vienna, Austria, 2012.

14. Hammer, O.; Harper, D.A.T.; Ryan, P.D. PAST: Palaeontological statistics software package for education and data analysis. Palaeontol. Electron. 2001, 4, doi: 10.1007/s11430-010-4152-3.

15. Meekins, J.F.; McCarthy, B.C. Competitive ability of Alliaria petiolata (garlic mustard, Brassicaceae), an invasive, nonindigenous forest herb. Int. J. Plant Sci. 1999, 160, 743-752.

16. Winterer, J.; Walsh, M.C.; Poddar, M.; Brennan, J.W.; Primak, S.M. Spatial and temporal segregation of juvenile and mature garlic mustard plants (Alliaria petiolata) in a central Pennsylvania Woodland. Am. Midl. Nat. 2005, 153, 209-216.

17. Nuzzo, V.A. Element Stewardship Abstract for Alliaria petiolata, Garlic Mustard; The Nature Conservancy: Arlington, VA, USA, 2000.

18. Carlson, A.M.; Gorchov, D.L. Effects of herbicide on the invasive biennial Alliaria petiolata (garlic mustard) and initial responses of native plants in a southwestern Ohio forest. Restor. Ecol. 2004, 12, 559-567.

19. Hochstedler, W.W.; Slaughter, B.S.; Gorchov, D.L.; Saunders, L.P.; Stevens, M.H. Forest floor plant community response to experimental control of the invasive biennial, Alliaria petiolata (garlic mustard). J. Torrey Bot. Soc. 2007, 134, 155-165. 
20. Slaughter, B.S.; Hochstedler, W.W.; Gorchov, D.L.; Carlson, A.M. Response of Alliaria petiolata (garlic mustard) to five years of fall herbicide application in a southern Ohio deciduous forest. $J$. Torrey Bot. Soc. 2007, 134, 18-26.

(C) 2012 by the authors; licensee MDPI, Basel, Switzerland. This article is an open access article distributed under the terms and conditions of the Creative Commons Attribution license (http://creativecommons.org/licenses/by/3.0/). 